Resenha 



\title{
Judiciário trabalhista e relações de trabalho no Brasil: relativizando teses, enterrando mitos
}

\author{
Valéria Marques Lobo*
}

SILVA, Fernando Teixeira. Trabalhadores no Tribunal: conflitos e Justiça do Trabalho em São Paulo no contexto do Golpe de 1964. São Paulo: Alameda, 2016.

Palavras-chave: Justiça do Trabalho; luta por direitos; Golpe de 1964.

Criada na conjuntura entre guerras durante o governo autoritário do Estado Novo, a Justiça do Trabalho foi formada a partir de influências externas múltiplas. Embora em suas origens estivesse impresso o objetivo de fomentar a paz social e evitar que o conflito entre capital e trabalho extravasasse o âmbito institucional - favorecendo assim o controle sobre os trabalhadores e suas demandas -, no decorrer de sua trajetória a Justiça do Trabalho tornou-se uma arena de disputas permanente, na qual os trabalhadores, por diversas vezes e em diferentes conjunturas, saíram vitoriosos, tanto no sentido de fazer valer direitos inscritos em lei quanto na conquista de direitos fixados em virtude do poder normativo de que dispõe a instituição. Em várias ocasiões os tribunais significaram para os trabalhadores o lugar da obtenção de ganhos acima daqueles obtidos por meio do confronto direto com o patronato, a despeito do enfrentamento ser árduo em ambas as esferas. Nesse ponto, cumpre mencionar que, não obstante ser parte do complexo corporativo e possuir a prerrogativa de promover a conciliação, historicamente a Justiça do Trabalho chegou, em determinados momentos, a incentivar a negociação direta entre patrões e empregados. Além disso, o Judiciário trabalhista fomentou, ainda que de forma incidental e pontual, a mobilização grevista. Por outro lado, os magistrados muitas vezes promoveram a isonomia de direitos entre os trabalhadores, amenizando o caráter segmentado que tipifica a ação coletiva dos trabalhadores e a estrutura de benefícios no âmbito do corporativismo.

Grosso modo, assim se caracteriza a instituição descrita e analisada por Fernando Teixeira da Silva em Trabalhadores no Tribunal: conflitos e Justiça do Trabalho em São Paulo no contexto do Golpe de 1964. Bem diferente da perspectiva predominante há 20 anos, quando vieram a público os resultados das primeiras pesquisas realizadas na área de História com base nos processos trabalhistas, devidamente elencados e comentados pelo autor.

* Professora do Departamento e do PPG em História da Universidade Federal de Juiz de Fora. 
Até os anos 90, predominava uma visão segundo a qual a JT, assim como todo o complexo corporativo, inibia a greve e mitigava o confronto direto entre patrões e empregados, em prejuízo desses. A estrutura corporativa destinavase a promover a paz social necessária à acumulação capitalista e o Judiciário trabalhista não passava de uma "justiça de classe". A presença de tal estrutura teria sido decisiva para o desenrolar dos acontecimentos que desaguaram no golpe civil-militar de 64, seja porque as lideranças trabalhistas e comunistas teriam aderido incondicionalmente à "lógica populista de controle da classe trabalhadora, impedindo que essa construísse uma política alternativa e independente" que fosse capaz de sobreviver ao "colapso do populismo", seja porque, às vésperas de 64, as instituições herdadas do Estado Novo já não eram capazes de canalizar o conflito social, o qual transbordou e abriu caminho para a ruptura institucional.

Tal percepção tem sido progressivamente revista à medida que a historiografia a respeito da ação coletiva dos trabalhadores brasileiros avança e passa a incluir estudos sobre o cotidiano das instituições legadas pelo Estado Novo, destinadas originalmente a controlar as relações de trabalho. Buscando enxergar além dos objetivos que orientaram o processo de formação daquelas instituições, tais estudos vêm descortinando um horizonte de mobilizações, lutas e conquistas que durante muitos anos havia sido negligenciado nos meios acadêmicos. Recentemente publicada pela editora Alameda, a tese de livre docência de Fernando Teixeira da Silva, cuja hipótese central é que o golpe de 64 decorreu do fortalecimento da luta por direitos dos trabalhadores brasileiros, processada a partir da institucionalidade herdada do Estado Novo, oferece contribuição inestimável no sentido de elucidar a história da Justiça do Trabalho e, por conseguinte, da própria estrutura de relações de trabalho brasileira.

Mais comentada do que pesquisada, como lembra o autor, a Justiça do Trabalho foi alvo de críticas da direita à esquerda do espectro político, muitas das quais informadas por mitos que se criaram em torno das instituições corporativas, das relações de trabalho, da relação entre Estado e sociedade no Brasil e da própria sociedade brasileira. Constituem mitos na medida em que não se baseiam em fatos. Emergem das ideias e são por elas alimentadas, sem qualquer vínculo com uma realidade que só poderia ser desvelada a partir de uma criteriosa investigação empírica, tal como se verifica em Trabalhadores no Tribunal: (...). Adicionando a análise de um considerável volume documental e de extensa bibliografia ao rigor metodológico, Fernando Teixeira da Silva trabalha em uma chave interpretativa que contribui para o desmonte paulatino daqueles mitos.

No primeiro capítulo, Silva repisa os antecedentes do arcabouço legislativo e jurídico erigido durante o primeiro governo Vargas para atestar que "quando da 'Revolução de 30', à qual muito se atribuiu a paternidade da legislação social no Brasil, já havia no país instituições, práticas e debates jurídicos e políticos que deitaram raízes no corporativismo getulista" (SILVA, p. 37). Além disso, por meio de uma cuidadosa revisão da literatura referente ao Direito do Trabalho no Brasil, o autor conclui que a JT, bem como a estrutura corporativa que lhe dá suporte, mais do que invólucro da dominação burguesa, consiste historicamente em um campo de batalhas das quais os trabalhadores por diversas vezes e em diferentes conjunturas saíram vitoriosos, inclusive porque souberam se apropriar e instrumentalizar a seu favor as instituições legadas pelo Estado Novo. Se tal perspectiva já não pode ser considerada inovadora, tendo em vista que as hipóteses que apontam nessa direção têm sido testadas há algum tempo por outros pesquisadores, o capítulo possui o mérito de reunir toda essa historiografia e travar com ela um debate permanente, 
para, no balanço final, corroborar com propriedade as teses que rejeitam o mito de uma Justiça a serviço dos interesses governamentais e empresariais, destinada a promover a conciliação e, por conseguinte, a paz social tão cara ao projeto de acumulação capitalista.

No segundo capítulo, também historiográfico, o autor amplia o horizonte da investigação para dialogar com uma literatura voltada para a compreensão não apenas do caso brasileiro, mas de situações internacionais diversas. Após observar, por meio dessa literatura, legislações, práticas e negociações concernentes às relações de trabalho em outros países e confrontá-las com o cenário nacional, Silva contribui para derrubar o mito que se criou em torno de um suposto hiato entre o sistema legislado de relações de trabalho, vigente em países como o Brasil, e o modelo contratual que predomina em países como a Inglaterra. Ao contrário de uma perspectiva binária, e de certa forma reducionista, o autor opta por compreender tais modelos em toda a sua complexidade, identificando traços intercambiáveis e indicando a presença de inúmeras características que seriam típicas de um modelo no outro. Dessa forma, o autor rompe com a acepção de que, no corporativismo brasileiro, dado o caráterheterônomo inscrito em suagênese, o Estadoédeterminante das leis, das instituições, das práticas e das interações que envolvem as relações de trabalho; ao passo que onde vigem sistemas negociados, a autonomia para firmar contratos é absoluta, o que asseguraria aos trabalhadores maior capacidade de mobilização, pressão, barganha e conquistas. Ao cabo, contrariando tal assertiva, o autor aponta a possibilidade, levantada por Tamara Lothian, e seguramente carente ainda de estudos que ofereçam mais subsídios à afirmação, "de que é nos países com regimes corporativos que o movimento operário mais tem se tornado 'vigoroso, independente e politizado"" (SILVA, p. 77).

No terceiro capítulo, ainda na perspectiva de contrastar o modelo brasileiro com outras realidades, o autor atribui viés ideológico à postura dos que sustentam o mito de que a Justiça do Trabalho corresponde a uma cópia fiel da Magistratura del Lavoro da Itália fascista, posto que tal característica subsidiaria a defesa de reformas na instituição ou mesmo sua supressão. Mobilizando literatura diversificada, Silva reflete acerca do que denomina de "fantasmas do corporativismo", para concluir que o Direito do Trabalho no Brasil bebeu em fontes italianas e em outras tantas que lhe serviram de inspiração e estão na origem de aspectos específicos da estrutura corporativa em geral e da Justiça do Trabalho em particular. A presença de vogais no Judiciário trabalhista brasileiro até 1988, por exemplo, marca uma diferença importante em relação à Magistratura del Lavoro, tendo em vista que os juízes classistas foram abolidos dos tribunais do trabalho italianos ainda nos anos 1920. Por outro lado, o autor destaca as semelhanças entre a Justiça trabalhista brasileira e a da República de Weimar, bem como aos casos de Portugal, México e Suécia, semelhanças essas pouco exploradas ou mesmo sequer mencionadas em boa parte das referências à Justiça do Trabalho. O autor ressalta, ainda, que mesmo que tenha recebido alguma influência italiana na origem, a instituição sobreviveu à ditadura estadonovista, passando por uma série de mudanças que revelam sua forte capacidade de adaptação. Esse capítulo, que encerra a parte historiográfica do livro, embora originalmente publicado em 2010, é de grande atualidade e, em conjunto com os demais capítulos que compõem essa primeira parte, resulta em um balanço primoroso da literatura a respeito da Justiça do Trabalho, constituindo hoje, talvez, o melhor ponto de partida, uma excelente escolha tanto para quem deseja ter um primeiro contato com o tema como para aqueles interessados em se atualizar na matéria. 
Na segunda parte do livro, mais empírica, o autor segue derrubando mitos.

No quarto capítulo, ao discutir a relação entre a ação dos trabalhadores e sindicatos junto à Justiça do Trabalho e na negociação direta com o patronato, o autor sugere, após pesquisa baseada em um volume considerável de processos trabalhistas do Tribunal Regional do Trabalho da $2^{\text {a }}$ Região (SP), que a presença da Justiça do Trabalho não apenas não inibe a mobilização dos trabalhadores em outras frentes de batalha, como a reforça. Ao discorrer sobre um período extremamente delicado da história política brasileira, compreendido entre 1963 e o golpe de 64, o autor analisa a atuação dos juízes colocados diante do desafio de decidir entre adotar posições informadas pelo "interesse público", colaborando, assim, com o plano governamental de conter a inflação, ou decidir em benefício da manutenção do poder aquisitivo dos salários dos trabalhadores. Isso, sob "forte e orquestrada" pressão dos empresários, que chamavam os magistrados à responsabilidade para com a paz social e o desenvolvimento da Nação. Ao mensurar os resultados obtidos nas negociações diretas ou com intermediação das delegacias regionais do Trabalho e aqueles obtidos nos tribunais, o autor apresenta várias conclusões importantes. Destaco três: 1 - as categorias com maior poder de barganha recorreram mais aos tribunais do que aquelas que dispunham de menor poder de pressão, as quais tendiam com frequência levemente maior a fixar acordos diretos com os patrões; 2 - nas cidades maiores e/ou mais industrializadas, onde os trabalhadores revelavam-se mais politizados e demonstravam maior capacidade de mobilização, ocorreram mais dissídios do que nas cidades menores; 3 - os dissídios aumentaram na segunda metade de 1963, período que coincide com a intensificação da mobilização em outras frentes. Tais constatações são suficientes para desmontar de forma definitiva o mito de que o Judiciário trabalhista e seu poder normativo mitigam a ação direta e a mobilização grevista. Mas o autor vai além e, ao confrontar resultados da ação em diferentes arenas, constata que é elevada a eficácia da ação junto à JT. O reajuste determinado em dissídio também tendia a ser maior que o estabelecido nos acordos extrajudiciais. Segundo Silva, a ação dos tribunais no sentido de assegurar o poder aquisitivo foi de tal ordem que, em 1965, foi retirada dos juízes a prerrogativa de fixar os índices de reajustamento. Por fim, merece destaque a constatação de que a JT pode ter uma atuação no sentido reduzir as disparidades salariais, matéria abordada também no capítulo seguinte. Nos termos do autor, os sindicatos mais fracos recorreram em peso aos tribunais visando a obtenção de índices mais robustos do que os que possivelmente seriam assegurados nas negociações diretas, tendo em vista a tendência dos tribunais de "fixar um mesmo patamar de direitos para os trabalhadores como um todo" (SILVA, p. 154).

O quinto capítulo se concentra nas decisões dos magistrados e desmonta de vez o mito de que "a arbitragem judicial converteria a negociação e a contratação coletivas 'em verdadeiros rituais desprovidos de qualquer significado econômico para os trabalhadores" (SILVA, p. 157). Atestando mais uma vez que a Justiça do Trabalho era uma arena de conflitos, o autor indica que nenhum dos atores adotava uma posição uniforme, mantendo uma postura unívoca diante de situações similares ou distintas. Pelo contrário, no que se refere particularmente aos juízes, nem todos agiam da mesma forma e boa parte tendia a considerar as alegações de ambas as partes em conflito na formação de sua posição, a qual não era, pois, predeterminada. Nesse ponto, cumpre destacar a posição dos vogais dos trabalhadores, por diversas vezes alvo de críticas por supostamente abandonar os interesses dos representados e acabarem votando com a representação patronal. 
Ao perscrutar os inúmeros processos, Silva revela que essa não é uma tendência, ao menos se considerados os processos do TRT-SP no período estudado pelo autor.

O capítulo VI analisa a relação entre a JT e o direito de greve. O autor percorre o debate legislativo e nos tribunais, bem como a legislação sobre o direito de greve, e conclui que não apenas a JT não inibe a greve, como em determinadas ocasiões o movimento paredista, ou a ameaça de paralisação, funcionou como mecanismo de pressão sobre o empresariado, induzindo-o à conciliação, tal como demonstra o pronunciamento de Alexandre Marcondes na Constituinte de 1946, em que afirma categoricamente que a greve pode ser positiva para forçar o patrão a conciliar. Ao cruzar dados referentes aos resultados de dissídios coletivos, o autor conclui que "os trabalhadores obtiveram mais direitos quando articularam greves e dissídios coletivos", ficando, pois, estabelecido que "entre 1945 e 1964, o instituto do dissídio coletivo no Brasil não foi incongruente com o direito de greve e seu exercício ou mesmo com a ação direta dos sindicatos e dos trabalhadores".

No capítulo VII, mais do que derrubar mitos, o livro contribui para a compreensão acerca da formação dos mesmos. Ao confrontar a trajetória do líder comunista Luiz Tenório de Lima, informada por sua memória, com os dados obtidos por meio dos processos trabalhistas, o autor identifica uma permanente ambiguidade entre uma narrativa crítica da Justiça do Trabalho, considerada uma "justiça de classe", e uma prática que, de diferentes maneiras, revela um reconhecimento quanto à efetividade de uma instituição não apenas destinada a promover os interesses dos trabalhadores, mas que, nas palavras do Tenorinho, militante nos anos 60, "pertence a eles". O livro narra episódios que atestam que o líder sindical recorreu aos tribunais tanto para buscar seus direitos individuais como em benefício de coletivos de trabalhadores. No entanto, ao publicar suas memórias, mais de 30 anos após ter sido preso pelo regime de 64, o ex-sindicalista, em benefício da "coerência autobiográfica", constrói uma narrativa que reforça a desconstrução do trabalhismo promovida durante a ditadura pelo próprio regime e endossada nos meios acadêmicos e mesmo sindicais. Nesse ponto, convém lembrar, ao lado de Silva, que os anos de "arrocho salarial' e de "arrolhamento do movimento sindical" teriam sido decisivos para a construção e o predomínio de uma imagem extremamente negativa do sistema de relações de trabalho erigido a partir dos anos 30. Da altura de seus quase oitenta anos, em plena década neoliberal, após ter enfrentado a mão pesada da ditadura e a postura crítica do novo sindicalismo, justifica-se a seletividade da memória de um Luiz Tenório já cansado de guerra ao construir uma narrativa que salva o militante comunista e a combatividade de seus companheiros, mas de certa forma subestima o espírito criativo de uma geração que, atuando no interior de um sistema destinado a controlar a ação coletiva dos trabalhadores e promover a conciliação, logrou transformá-lo de instrumento de controle em arena de conflitos, onde perderam e ganharam, tal como demonstra o livro que é objeto desta resenha.

Um balanço mais definitivo sobre o Judiciário trabalhista, em particular, e o sistema de relações de trabalho brasileiro, em geral, supõe novas pesquisas, para as quais as fontes da Justiça do Trabalho são cruciais. E também, nesse particular, Fernando Teixeira da Silva é preciso, ao destacar a importância da preservação dos processos trabalhistas em "capítulo-bônus" que, publicado originalmente há dez anos, quando se afirmava a luta pela preservação dos acervos da Justiça do Trabalho no país, encerra um livro, reitero, de valor inestimável.

Mesclando artigos anteriormente publicados com textos inéditos, o autor imprime rigor metodológico, análise fina e escrita agradável ao abordar temática 
mais do que relevante, sobretudo se considerarmos a presença hoje de uma conjuntura política talvez até mais delicada do que aquela sobre a qual o livro reflete. Lá, um golpe iminente daria origem a um regime que arrochou salários e chegou a subtrair direitos dos trabalhadores, mas de forma acanhada se contrastado com o cenário atual, quando, não obstante ter sua legitimidade questionada, o governo federal impõe uma agenda que ataca frontalmente o Direito do Trabalho em suas mais variadas faces tal como jamais ocorrera no país, nem mesmo nos governos militares ou na década neoliberal. Diante disso, a leitura e divulgação de Trabalhadores no Tribunal: (...), dada sua enorme contribuição no sentido de elucidar aspectos diversos do sistema brasileiro de relações de trabalho e sua história que comporta instituições das mais longevas do complexo institucional do país, torna-se urgente. Recomendo!

Enviado: $19 / 04 / 2017$

Aprovado: 31/08/2017 